\title{
The Future Role of the Nuclear Energy in Brazil in a Transition Energy Scenario
}

\author{
Fábio Branco Vaz de Oliveira, Kengo Imakuma, Delvonei Alves de Andrade \\ Nuclear and Energy Research Institute, Cidade Universitária, São Paulo, Brazil \\ Email: fabio@ipen.br, delvonei@ipen.br
}

Received 13 August 2014; revised 12 September 2014; accepted 30 September 2014

Copyright (C) 2014 by authors and Scientific Research Publishing Inc.

This work is licensed under the Creative Commons Attribution International License (CC BY). http://creativecommons.org/licenses/by/4.0/

(c) () Open Access

\section{Abstract}

This paper discusses and presents figures about the future power consumption in the world and, especially in Brazil, based on the current world and Brazilian's energy scenarios. Emphasis is given to the scenarios of nuclear power and uranium resources demand. A discussion on the future roles of thorium and uranium fuels in the replacement of the traditional resources like oil and gas is also presented, as it is the role of the new nuclear power plants, planned to be built in a short term time horizon. This paper considers two different indexes for future projections, and the results obtained indicated a strong dependence on them. The time horizon for the analysis was fixed on the time estimated for Brazil to reach its maximum in population, and parameters evaluated were taken from the Brazilian's governmental and world data on the population growth, energy consumption and energy consumption per capita. Calculations show that the power consumption projections for Brazil, for the adopted time horizon and working with global indexes, become overestimated, when compared with the results considering the national indexes. According to our approach, power consumption estimates using global indexes becomes approximately 4.5 times higher than the estimates presented by the Brazilian indexes. This was the motivation to the discussion between the Brazilian and world energy demand scenarios, and also the roles of nuclear energy in the future transition from the current conventional to alternative sources.

\section{Keywords}

Nuclear Energy, Renewables, Future Energetic Resources, Uranium, Projections

\section{Introduction}

The shortage of the most common used energy resources, such as oil, coal and water, and their growing consumption, together with the population growth and global warming, are phenomena clearly affecting the planet. The recent formation of tornadoes in the coast of Santa Catarina, which never happened or had been reported in 
all Brazilian history, the excessive melting of the polar ice caps, for example, can be foreshadows of a large scale global manifestations of uncontrolled and unpredictable climate changes, due to the exaggeration of the consumption of natural resources. Also, the increasing gap between economical and social classes and the pressure it exerts in the production of more expensive products, which also generates an enhancement in the energy consumption, clearly become an important issue on the countries future energetic planning. Besides the social and economical needs, planning must take into consideration the structure of the national energy matrix, and has to be based on what it can provide to support the country's growing perspectives. In this scenario, studies concerning the use and improvement in the technologies related to renewable or clean energies are growing and nuclear energy, among them, plays an important role.

Energy from renewable and nuclear resources, are considered candidates to reduce an incoming world energy crisis. Nuclear energy is one of the most promising candidates, despite the recent accident in Fukushima, since the technology is well developed and has a strong knowledge basis. Some countries are declining to build new nuclear plants. Nonetheless, it is interesting to note, for example, the acceleration of the construction of more secure power plants and the adequacy of the older ones to the new and more stringent security criteria in the world and in particular in United States. It shows a pressure in the production of energy, at least for this country. This can be an image of what might occur in the world in terms of energy consumption, but in a lesser scale, since United States, together which China, are the countries exerting the highest pressure in the consumption of the global energy resources [1] making their demands for energy more urgent. An argument which favors the utilization of nuclear energy is given, for example, in the work of Haratyk and Forsberg [2]. They devised a coupling between nuclear energy and renewable facilities. According to them, renewables cannot supply the increasing demand of energy in the short term, given the current countries technological status.

Thus, it is expected that nuclear energy will replace in a large scale and in a short term, the conventional resources, increasing its participation in international and national scenarios of energy demand. But it cannot be accomplished without a deep study about the future supply of nuclear fuels, mainly uranium and, for a more advanced perspective, thorium.

Both minerals are abundant in Brazil, and for the national projections, uranium is available in sufficient amounts to supply the four planned PWR reactors, to be constructed up to 2050 [3]. Even having the technology knowledge of all the fuel cycle, the energy matrix in Brazil is mainly hydroelectric and nuclear represents $3 \%$. In the world, nuclear energy is about $17 \%$ of the total generated electricity, and about $5.4 \%$ of the total world energy consumption. However, in a transition energy scenario, even with the recent discoveries of oil reserves in pre-salt formations in the Brazilian coast, having a potential to increase power in our energy matrix, with the construction of the Belo Monte hydroelectric power facility, abundance of solar radiation over the entire year covering all our territory, etc., nuclear power could be a short term solution of a possible energy supply delay, expected for the years to come, up to the development of the renewables technology to reach efficiency levels, suitable for commercial exploration. Besides, the development of the technology of the extraction and purification of the small amounts of uranium from the recent discovered phosphatic deposits [4], which covers almost one third in area of the Brazilian territory, will improve the reserves and also the capabilities of the expansion of its nuclear and, thus, energetic matrix.

The construction of nuclear power facilities is also a matter of public discussions, mainly concerned about the safety requirements and accident risks, which rises again after the recent Fukushima's accident. From the arguments above and the discussions to be presented in the next items, it is easy to see and, according to our opinion, that Brazil has a privileged position in terms of the availability of energy resources, including uranium. This privileged position could be used to overcome public rejection and to support the acceptance, even in the long term, to the Brazilian's initiative in the direction of the construction of new nuclear power facilities in Brazil, since massive investments in nuclear power, like those in United States and China, are not planned [3]. However, for a long term planning, energy consumption estimates must be calculated on reliable basis, emphasizing both the global and national scenarios in the current energy context.

This paper analyzes and estimates the future power consumption in the world and in Brazil, based on the current worlds and Brazilian's energy scenarios, with emphasis to the scenarios of nuclear power and uranium resources demand. A discussion about the future roles of thorium and uranium fuels in the replacement of the traditional resources like oil and gas, the advantages of thorium in terms of energetic efficiency, is also presented. As a consequence of the uses and availability of the nuclear fuels, the role of the new nuclear power plants, 
planned to be built in a short term time horizon, is also discussed in this same scenario. Emphasis was given to the called 2DS scenario [5], which means a scenario where it is predicted a minimum of $2^{\circ} \mathrm{C}$ for the increasing in the global mean temperature, up to 2025. Actions and plans are under discussion, each one of the possible new technologies having specific advantages and drawbacks [5].

The comparison presented in this paper pointed out a strong dependence on the two different indexes, used for future projections. Global indexes were extracted from the projections made in the Tomabechi's work [6] for the world consumption, which deals with the relation between energy consumption indexes and world's population growth as the parameter to be evaluated. These results were extended to make projections for the Brazilian case. Brazilian indexes were based on the national projections for the population growth, listed by IBGE [7] and were used for the future projections. To check for the importance of domestic scenarios in the projections, graphics are given to show the evolution and to compare global and domestic parameters such as population growth, power consumption per capita and total power consumption in some countries.

The time horizon for the analysis was fixed on the time estimated for Brazil to reach its maximum population, and parameters evaluated were taken from the Brazilian's governmental and world data on the population growth, energy consumption and energy consumption per capita.

This was the motivation to both discussions carried out here, one associating Brazil within a global transition scenario, and the other which dissociates our country from the global considerations, discussing our future projection results in a domestic perspective. Since nuclear is the prompt alternative instead of the undeveloped renewables technology, it is also discussed its role as the main alternative to the replacement of the current conventional ones.

\section{Nuclear Energy in a Transition Energy Scenario}

Concerning today’s debates regarding energy demand and global warming, a transition energy scenario, according to reference [5], means that world needs to change from the prevalent high-carbon/high-pollutant technologies to the incoming low-carbon/low pollutant ones, from the exploitation of the energy resources through the generation of energy. However, considering the phenomena of the development of those new technologies as a dynamical process, demanding time and consuming resources (energetic and monetary), it is known that it usually does not evolves with time at the same rate as that necessary to overcome the problems for the today's climate changes and energy consumption.

Since earth is a dynamical system, it is continuously changing, through changes in its observable properties with time. However, since the time human beings are exploring its resources, they become one of the major causes of changes on earth's properties, the most sensitive of them and most easily visualized and studied are those related to weather. The problem is, at the today's rates of consumption, these changes are possibly leading humanity to an irreversible path and, the worst of all, in a short period of time. Technology and human intelligence solved several problems of our everyday life, enabling us to go to the moon, to explore planets, the universe and the subatomic world, to defeat diseases, communication problems, etc., but its side effects is presenting itself as a very harm one.

Based on the current status of the renewable technology development and the growth of the mean earth's temperature, scientists devised 3 possible states for the future global weather, based on 3 possible values for the increase in the mean earth's temperature. Based on that, governments can take action plans to deal with these three possible scenarios; changes in the energy policy are necessary to be planned, defined and studied to provide approaches for the solution of the incoming energy problems. The above scenarios go from the minimum to the maximum harm for the living beings in the planet. They are called XDS scenarios, where $X=2,4$ or 6 and stands for the expected increase in the mean earth's temperature, in degrees C, for a fixed time horizon of 2025.

It is pointed out by reference [5] that energy technologies like solar and photovoltaic are promising to reach the 2DS requirements, but the ones with greatest potential to reduce carbon emissions, like the nuclear, are making the slowest progress, since security is the main topic of interest for the public acceptance and for its full utilization. It is expected a growth of $600 \mathrm{GW}$ of nuclear installed capacity to reach the 2DS requirements, but after the Fukushima's accident it is also expected a deployment in $100 \mathrm{GW}$, becoming this process a complicated one.

For the projections of the future of the energy supply by nuclear energy, the repercussion of the 2011 accident was fundamental, leading United States to review the current security criteria for the construction of the 22 
planned new nuclear power plants, which are based on the intrinsically safe AP1000PWR design, mostly from 100 MW to 300 MW power. Despite of its safety aspects, however, some authors still criticize its design, like Piore [8], who emphasizes that the security factors for the pressure vessel's project is undersized. For the breeder reactors, another technology being considered which enables the extension of the fuel's lifetime, Cochran [9] emphasizes the problem of the isolation of sodium and water lines, critical due to the risk of explosions. Those are issues that testify against the use of such technologies.

However, according to the World Nuclear Association data [10], in addition to the today's 441 nuclear reactors in the world, more 338 nuclear reactors are planned to be constructed, four in Brazil [10]. Based on the same report [10], in 201183 reactors were under construction, most of them are PWR, according to Table 1.

On June 1st, 2010, Brazil restarts the construction of the Angra III nuclear power reactor and, together with the planned four, as stated recently in 2012. Our supply of nuclear power will increase in approximately 5300 MW. More ambitious construction plans are presented by China, Russia, United States and Ukraine which are planning to build, respectively, 115, 40, 30, 28 and 20 more nuclear power reactors, a total of 223, mostly based on the LWR technologies. Thus, despite the accident and the rising of the unfavorable public opinion against the construction of new nuclear power plants, it is observed [5] that most of the countries kept their nuclear programs active. But the only factor that has changed is the speed on which the new facilities are planned to be constructed.

Another favorable point for the installation of new nuclear plants was devised by WEC [11], also having as basis that this technology is well developed. In this document it was suggested that, to accelerate the transition from Green House Gas, GHG, to non-GHG technologies, nuclear expertise could be shared from the nuclear developed countries to the non-developed ones. According to WEC [11], this could be another way of global scale cooperation for the reduction of GHG emissions and to develop the 3rd world technological infrastructure, aiming the minimization of the time for an undeveloped country to reach an acceptable level of technology to deploy clean energy technologies. Also, [11] states that new rules for patent interchange and utilization must be redefined, for the humankind to adapt to the new survival requirements. Sharing costs could be viewed by the leading technological countries in the world as a logical path. Since global warming and energy consumption is a world problem, large-scale technology as well as costs should be diffused at same basis in order to share a solution in the direction of the reduction of the global costs of the pollution through the deployment, for example, of the clean energy technologies. This is an important point of debate in the more recent seminars on greenhouse gas emissions and the future of the climate of the planet

We have to keep in mind that important differences arise if the scenario for the estimates is taken locally. For example, countries with high number of nuclear reactors, large populations and with large energy consumption, like United States, China, European Union, etc., global indexes obviously do not reflect the truth about the national estimates for these countries, since they pull the mean world values of consumption/demand of electricity upwards. For example, in terms of the greenhouse gas emissions, it is observed that $50 \%$ of the total is due to oil and coal usage, mainly from United States and China. Thus, there is a mistake of sharing the indexes/costs. It is suggested here a criterion for the evaluation of a real "contribution" of a country for the global energy consumption.

For Brazil, the technology for clean energy deployment is still in a growing phase for some of the renewables, in terms of the domestic energy supply index. According to Cerri [12], 41\% of Brazil's total domestic energy supply comes from renewable resources, against $14 \%$ as a mean value in the world and $6 \%$ in industrialized countries.

\begin{tabular}{cc} 
Table 1. Nuclear reactors under construction or “almost so”, by design [10]. \\
\hline Reactor Design & Quantity \\
\hline Fast Breeder Reactor & 02 \\
Pressurized Water Reactor & $61($ China $=26)$ \\
Pressurized Heavy Water Reactor & 11 \\
Advanced Boiling Water Reactor & 08 \\
High Temperature Gas Reactor & 01 \\
Total & 83 \\
\hline
\end{tabular}


This outcome implies a reduced dependence for imports of energy sources, and an advantage in terms of energy supply for the future, even its nuclear park representing only $3 \%$ of the total energetic production. Thus, the use of local indexes could be a better choice, for a better accuracy for projections of energy consumption. But it is important to observe that Brazil holds the position to be one of the top green-house gas emitters in the world, mainly due to the deforestation to livestock and agricultural uses [12].

\section{The Uranium Scenario}

To see how uranium resources can provide a short term solution to face a possible energy supply crisis, it is convenient to compare the world's uranium reserves capabilities with those of oil and coal, the most used natural resources in the world.

For generating $375 \mathrm{GWe}$, the corresponding electricity generated by nuclear fissions, it is required 68,000 $\mathrm{t}$ of uranium per year. According to Table 2 [13], and ignoring the so called secondary sources of uranium (uranium from nuclear weapons, reprocessing, etc.), if the total estimated amount of uranium metal is $5.5 \mathrm{Mt}$, at the above rate of consumption the uranium reserves will last 80.8 years. This amount is enough to reach the so called 2DS objectives up to 2025 [5], where the required power related to nuclear energy is about 600 GWe. The difference of $225 \mathrm{GW}$ corresponds to 40,000 t of uranium per year, an enough amount to cover 2DS requirements. As explained below, the Fukushima accident changed some policies related to the construction and operation of new nuclear power plants, the value of $600 \mathrm{GWe}$ must be reduced for this reason.

In terms of oil, based on the current consumption rate, $8.2 \times 10^{7}$ barrels/day, and considering it as constant, a non-realistic hypothesis, its length can be calculated in almost 41 years. United States is the planet's largest consumer of this resource, with approximately $1.9 \times 10^{7}$ barrels/day, nearly $25 \%$ of the world's consumption, and Brazil appears in seventh place, $2.5 \times 10^{6}$ barrels/day. Regarding coal, China is in the first place, with $1.31 \times$ $10^{9}$ tons/year, followed by the United States, with $1.06 \times 10^{9}$ tons/year, and together account for $50 \%$ of the world's total consumption, and also for the corresponding greenhouse gas emissions. Brazil appears in 19th

Table 2. Known recoverable resources of uranium (Reasonably Assured Resources plus Inferred Resources, to US\$130/kg U, 1/1/09, from OECD NEA \& IAEA [10]).

\begin{tabular}{ccc}
\hline Country & Tons of uranium & \% of world's total \\
\hline Australia & $1,673,000$ & 31.0 \\
Kazakhstan & 651,000 & 12.0 \\
Canada & 485,000 & 9.0 \\
Russian Federation & 480,000 & 9.0 \\
South Africa & 295,000 & 5.5 \\
Namibia & 284,000 & 5.0 \\
Brazil & 279,000 & 5.0 \\
Niger & 272,000 & 5.0 \\
United States & 207,000 & 4.0 \\
China & 171,000 & 3.0 \\
Jordan & 112,000 & 2.0 \\
Uzbekistan & 111,000 & 2.0 \\
Ukraine & 105,000 & 2.0 \\
India & 80,000 & 1.5 \\
Mongolia & 49,000 & 1.0 \\
Other countries & 150,000 & 3.0 \\
World total & $5,404,000$ & $100 \%$ \\
\hline & & \\
\hline & & 2.0 \\
\hline
\end{tabular}


place, with $2.3 \times 10^{7}$ tons/year, twice orders of magnitude less than the previous two [14]. In terms of proved coal reserves, considering that there are around 522 billion tons, the current consumption rate of $4.59 \times 10^{9}$ tons/day [14], and supposing that rate remains constant for the following years, we can estimate that the reserves will last 113 years. In both cases, uranium can be seen as the readiest resource for their possible replacement. For example, as previously mentioned, primary resources of uranium will end, at the current consumption rate, in about 80 years, in the mean value, accounted for the world, not for a particular country figure.

For Brazil, with the estimated growth scenarios for our nuclear matrix [15], from the current $1.95 \mathrm{GW}$ to 3.5 up to $7 \mathrm{GW}$, our reserves will last 120 to 240 years (reserves of uranium considered at a total cost of less than US\$ 130/kg, the criteria for an economical exploration of an uranium mine) and from 200 to 400 years, taking into account also the inferred reserves. A safer estimate, which predicts a maximum percentage of the total electricity generated by the Brazilian nuclear matrix of 5.7\%, excluding the estimated by INB [4] inferred reserves of 800,000 tons, the duration of our uranium resources is, in the worst scenario, about 90 years. Taking into account these reserves, together with the 279,000 ton of uranium metal, the estimates are for the operation of 10 nuclear reactors like Angra III, for 200 years [16]. The problem is that most of the uranium in the inferred reserves comes from phosphates, and the technique for uranium extraction from phosphates is still uneconomical. The same problem in terms of the costs/economy of extraction is presented with the uranium obtained from sea water, whose amount is estimated in $3.3 \mathrm{ppb}$ [6].

Since most of the energy generated in Brazil is from hydropower, and since the water resources are now limited due to considerations of preservation and other environmental aspects [16], to cope with the hydropower restraint in terms of space, nuclear expansion in terms of the self-sustained scenario would be helpful, according to the data presented in Table 3 presented in the next item.

Thorium is another source of fissionable isotope, $U^{233}$, its reserves are estimated to be 3 times higher than uranium's. In the work of Ashley [17], it was stated that the amount of thorium as a by-product of rare earth processing would be enough to feed 200 nuclear ADTR (“Advanced Thorium Reactor"), without the need to open new mines for exploration and extraction, thus with no initial investments. Also, other advantage of thorium compared to uranium is its total usage as nuclear fuel as extracted from the mines, instead of the $0.7 \%$ relating to the fissile isotope $\mathrm{U}^{235}$, present in $\mathrm{U}^{238}$ matrix. It means, according to Ashley [17] that for each $\mathrm{GW}$ of electricity produced, only 1 ton of mined thorium is necessary, whereas 200 tons of uranium from the mines or 3.5 Mt of coal would be required to produce the same amount of electricity.

Although there are still doubts about the real need for the construction of new nuclear power plants in Brazil, the debate is still open, and the numbers shown in the tables and the scenarios presented above are favorable. Considering the capabilities of the Brazilian nuclear reserves, it will be described and simulated, in the next items, some possible scenarios for its utilization in relation to two parameters, among the huge numbers of variables that usually affect a more complete analysis, population growth and energy consumption.

The scenarios for the national analysis were taken from the Plano Nuclear Brasileiro 2030 ("Brazilian Nuclear Plan 2030”) [18], from EPE and Eletronuclear. A comparison will be made with results found in recent literature.

\section{Projections: Energy Consumption and Demand, and Population Growth}

Since population and the energy consumption growths are some of the most significant parameters to pressure energy demand, the projections for the Brazilian population growth, presented by the data of IBGE [7] in Figure 1 , are firstly analyzed before the estimates of energy needs. Other sources for population growth projections are available, like the CIA fact book [1]. According to IBGE, the maximum in Brazilian population will occur in

Table 3. Electricity consumption generated via nuclear power, for inhabitant year, according to the scenarios of the PNB 2030 and using Equation (2).

\begin{tabular}{ccc}
\hline Scenarios of growth & Year 2030 [MJ/(inhab. year)] & Year 2040 [MJ/(inhab. year)] \\
\hline Minimum (2.7\%) & 190.89 & 200.34 \\
Development (4.2\%) & 296.94 & 311.64 \\
Self-sustainable (5.7\%) & 402.99 & 422.94 \\
\hline
\end{tabular}




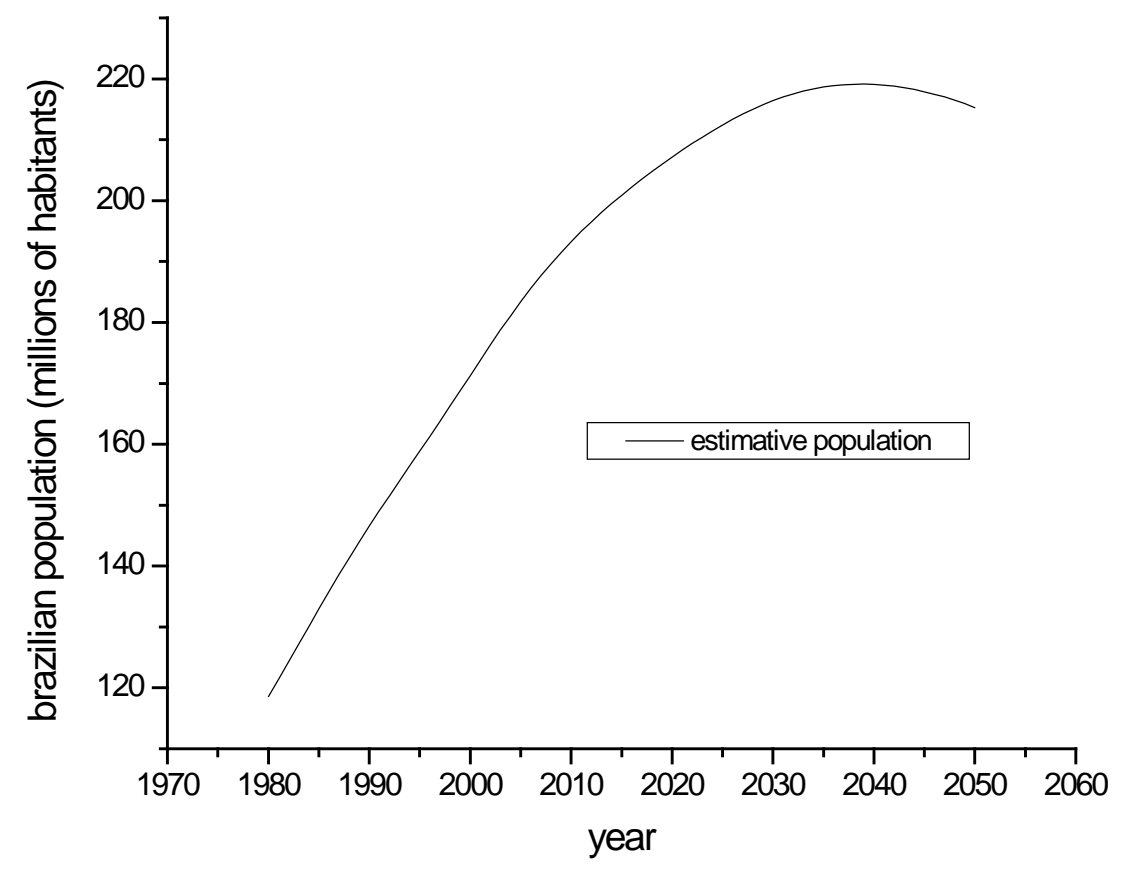

Figure 1. Brazilian population projection, up to 2050 [7].

2039 (219,124,700 inhabitants). However, between 2020 and 2030, the limits of the proposed energetic planning horizons [3] [19], our population will have approximately 212 million inhabitants.

The parameter energy consumption growth, would give accurate predictions if analyzed for each country, instead of taking the estimates based on global indexes. To put both parameters together, we observe that Iceland has the highest index of energy consumption per capita in the world, but its population is below 5 million people, meaning its contribution to the total world energy consumption is low. Countries with the highest energy consumption per capita are China, the United States, Japan, Russia, India, Canada, South Korea, South Africa, Australia, and the European Union. Taking together population growth and absolute population, these countries are not the first ranked ones (in terms of growth rate, East Timor, with $4.5 \%$ by year, is in the first place [1]), but pressure the energy consumption by their high number of inhabitants and also by their high energy consumption per capita. The Brazilian energy consumption per capita can be seen in Figure 2. The consumption per capita for the most populated countries is given in Figure 3, to acquaint for the differences mentioned in the introduction.

In terms of world energy consumption, it is important to observe that countries of the Europe and North America have lower population growth rates, but their energy consumption is about 1 order of magnitude higher than the mean world energy consumption. This is shown in Figure 4 and Figure 5.

In a recent paper from Tomabechi [6], it was estimated that when the world population reaches $\mathbf{N}_{\mathrm{hm}}=10$ billion inhabitants, around the next 30 to 50 years, according to the current global mean population growth of 81 million people/year, the energy demand will be $\mathbf{C}_{\mathbf{m}}=2 \mathrm{ZJ} /$ year (where $1 \mathrm{Z}=10^{21}$ ). This number was defined, according to the authors, based on data about the energy resource consumption of developed countries, extended to all the countries of the world. Thus, the estimated energy world consumption per inhabitant ("per capita"), $\mathbf{C}_{\mathbf{p c}}$, at the time of $\mathbf{N}_{\mathrm{hm}}$, would be:

$$
\mathbf{C}_{\mathbf{p c}}=\mathbf{C}_{\mathbf{m}} / \mathbf{N}_{\mathrm{hm}}=\left[2 \times 10^{21}(\mathrm{ZJ} / \text { year }) / 10^{10}(\text { inhabitants })\right]=\mathbf{2 0 0} \mathrm{BJ} /(\text { inhabitant } \cdot \text { year })
$$

where BJ $=10^{9} \mathrm{~J}=$ billion Joules, for a hypothetical scenario which predicts equality in the future energy consumption pattern for all the world's population. It is shown in the following graphs that the developed countries are in general the largest energy consumers, and having the highest energy per capita consumption rates, just to confirm that global indexes do not represent local realities.

According to the indexes presented by Tomabechi [6], to start the projections of $\mathbf{N}_{\mathbf{h m}}$, since nuclear power accounts for approximately $5.4 \%$ of the total energy consumption in the world [1], the demand for this resource would be: 


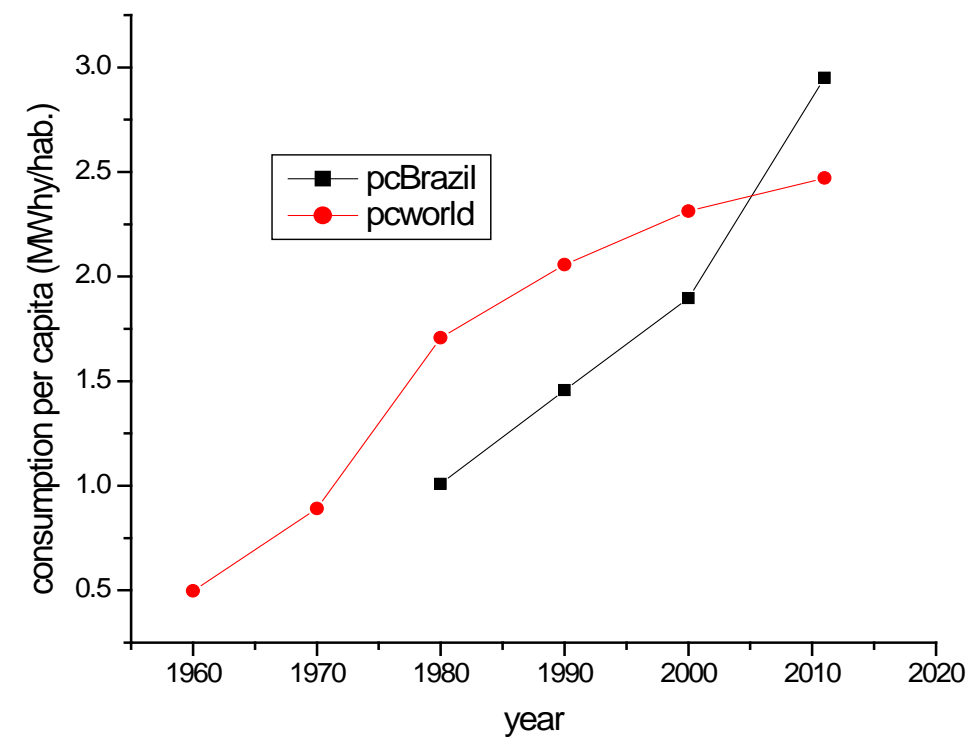

Figure 2. Consumption per capita, Brazil.

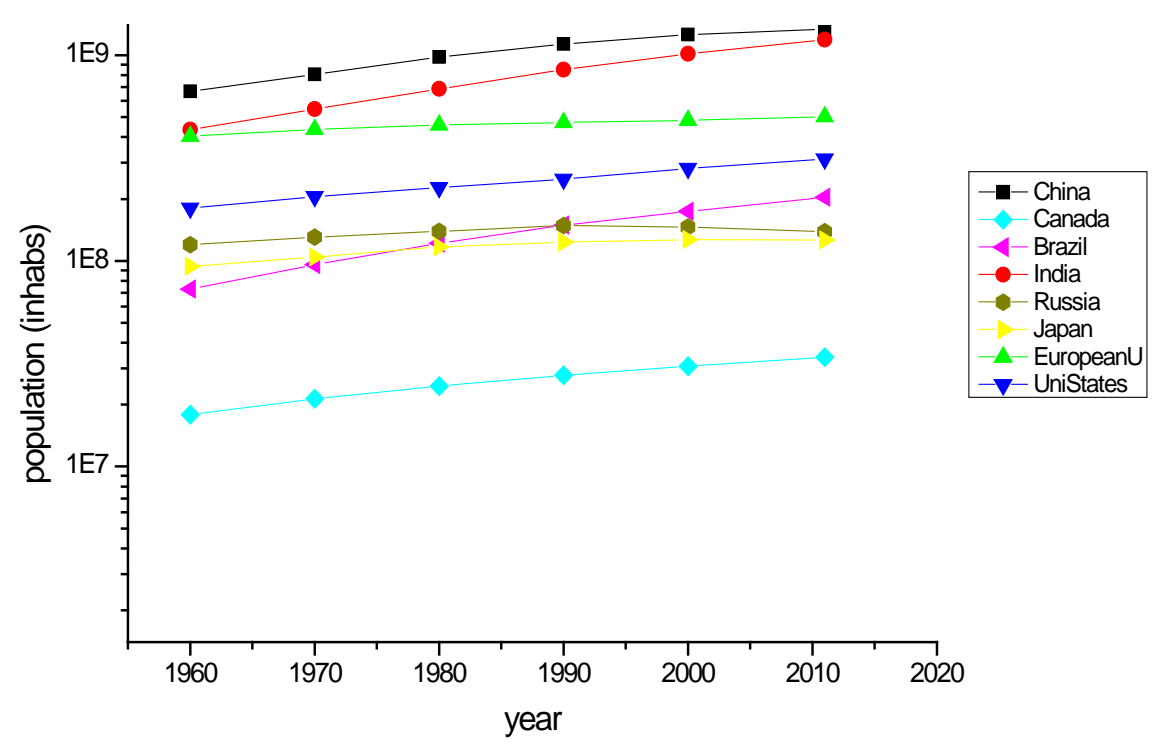

Figure 3. Population growth of the most populated countries.

$$
\mathbf{C}_{\text {pcnuke }}=10.8 \mathrm{BJ} /(\text { inhabitant year })
$$

From the IBGE data [7], in 25 years, the Brazilian population $\mathbf{N}_{\mathbf{h B r}}$ will reach its maximum at $219 \mathrm{M}$ inhabitants (Figure 1, where $1 \mathrm{M}=10^{6}$ ), at about the same time the world population is estimated to reach $\mathbf{N}_{\mathbf{h m}}$. It can be predicted that, taking into account the above hypothesis, the Brazilian energy consumption per year, $\mathbf{C}_{\mathbf{B r}}$, will be:

$$
\mathrm{C}_{\mathrm{Br}}=\mathrm{Cpc} \cdot \mathrm{N}_{\mathrm{hBr}}=200 \times 10^{9}(\mathrm{~J} / \text { inhabitant year }) \times 219 \times 10^{6}(\text { inhabitant })=\mathbf{0 . 0 4 3 8} \mathbf{Z J} / \text { year }
$$

corresponding to $2.19 \%$ of the global energy needs.

From an estimate based on the data of the 2005 Brazilian National Energy Balance presented in [15], assuming a constant growth rate of $0.67 \%$ per year in relation to the total energy consumption, and $0.64 \%$ relating to the electricity consumption, some estimates can be carried for the total energy consumption per inhabitant in Brazil, $\mathbf{C}_{\mathbf{p c B r t o t a l}}$. 


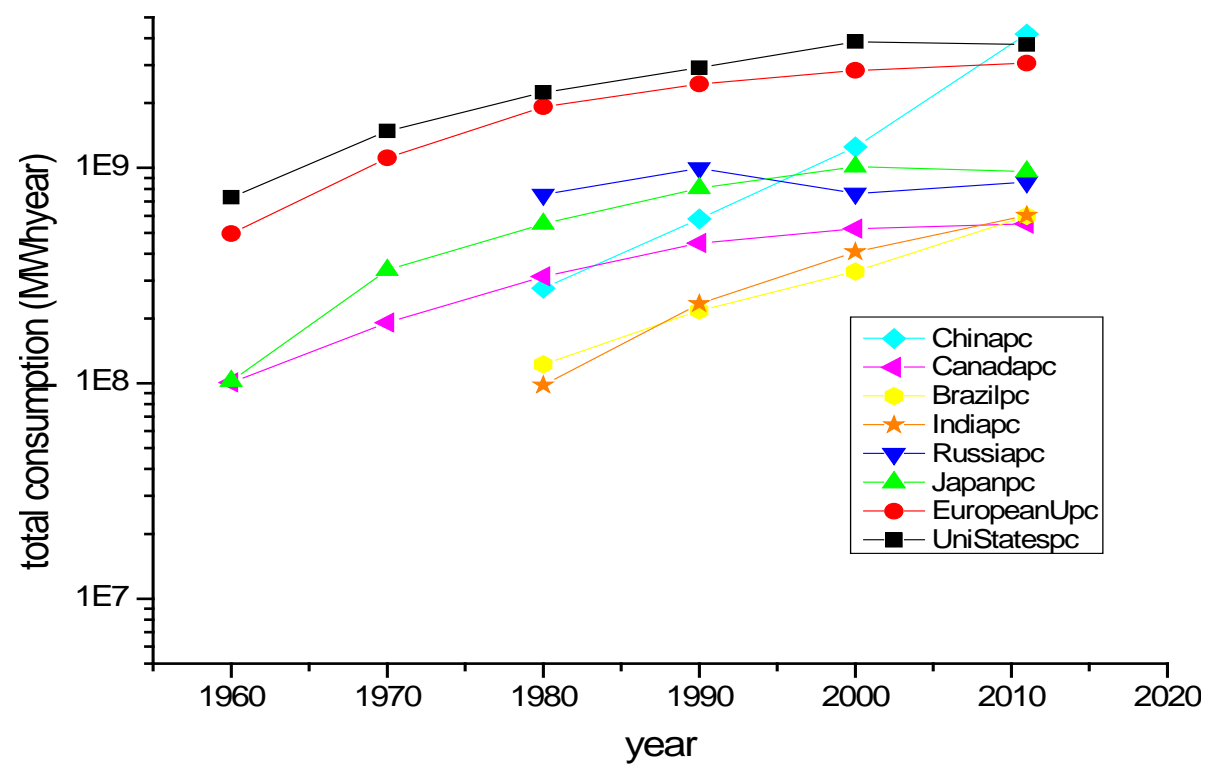

Figure 4. For the same countries of Figure 3, total energy consumption.

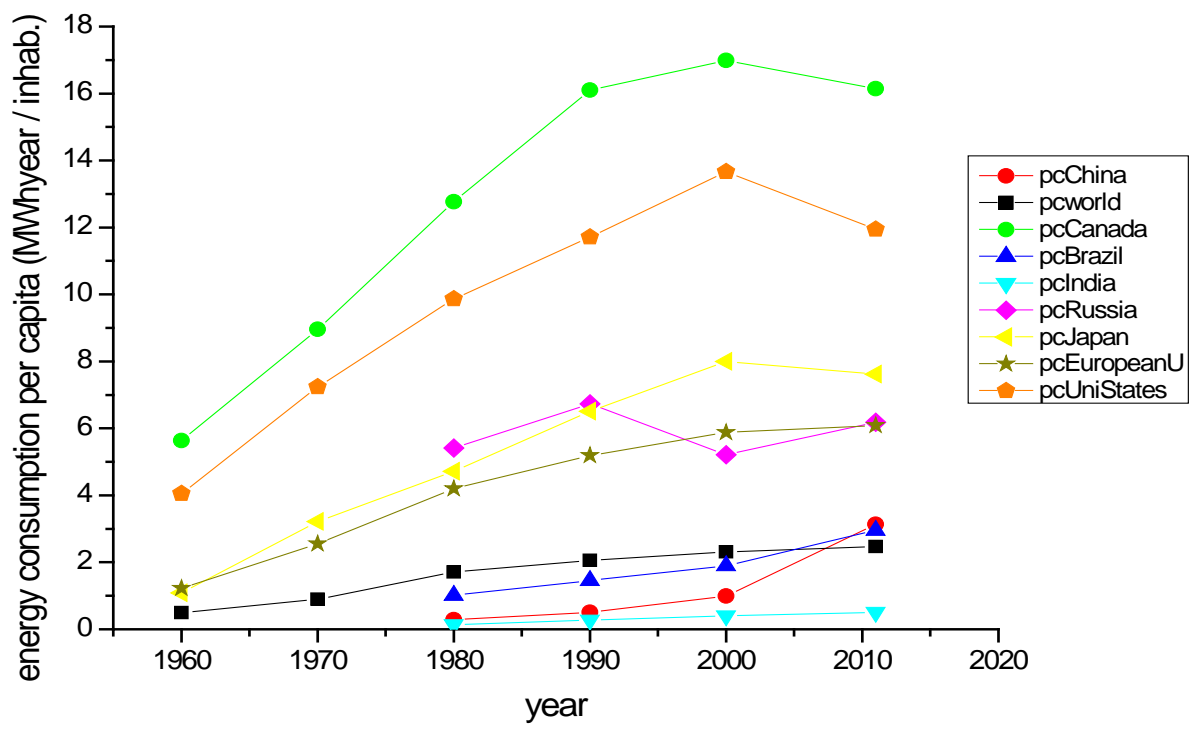

Figure 5. For the same countries, energy consumption per capita.

First, for the total energy consumption, the result is, for 2030:

$$
\mathbf{C}_{\text {pcBrtotal }}=\left[9.518 \times 10^{-3}(\mathrm{ZJ} / \text { year }) / 216,010,430(\text { inhabitants })\right]=44.1 \mathrm{BJ} /(\text { inhabitant year })
$$

and for 2039:

$$
\mathbf{C}_{\text {pcBrtotal }}=\left[1.0175 \times 10^{-2}(\mathrm{ZJ} / \text { year }) / 219,124,700(\text { inhabitants })\right]=46.4 \mathrm{BJ} /(\text { inhabitant year })
$$

both results nearly 4.5 times lower than the value of $\mathrm{C}_{\mathrm{pc}}$, predicted according to Tomabechi methodology [6], and to the relation in Equation (2). This result shows that the differences can be very high if the estimates are taken from global indexes, which are average values, justifying the use of domestic indexes for the estimates. The goal is not to criticize or favor any methodology, but just to point out that there is a need to present them comparatively, if working together on the reduction or sharing pollution/clean energies deployment costs.

Taking into account a Brazilian scenario provided by EPE/Eletronuclear [15] about the future participation of 
the nuclear power in the energy matrix in Brazil, and the INB [4] projections for the Brazilian uranium supplies, its future contribution to the energy demand can be estimated, and the results compared to those from Equation (2).

According to the scenario devised in the EPE document [15], nuclear energy participation in the national electricity demand would grow from the current $2.5 \%$ (from a current national total of $78 \mathrm{GW}$ ) to $2.7 \%$. Thus, it will be necessary one more nuclear power plant with capacity of 100 to $300 \mathrm{MW}$ and the nuclear matrix will grow from 1950 MW to a maximum of 3550 MW, considering also the construction of Angra III. This work also stated that, in a so called simple development scenario, the estimated participation of nuclear would be $4.2 \%$, comprising the construction of one more nuclear power plant 1300 MW power, (together with Angra III) and two other nuclear power plants of $300 \mathrm{MW}$ each, adding $3200 \mathrm{MW}$ to the current $1950 \mathrm{MW}$, and making up a total of 5150 MW. Finally, in a so called self-sustained development scenario, more interesting to the safe future supply of energy for the next generations, an increase of $5.7 \%$ would be supported by the construction of two new nuclear power plants 1300 MW power each (together with Angra III), and four more new modular stations $300 \mathrm{MW}$ power each. The electricity generation capacity via nuclear power would grow from the current 1950 MW to 6950 MW.

Thus, the participation in the energy consumption in Brazil per inhabitant in relation to nuclear energy can be estimated according to those three scenarios, and the results are shown in Table 3, where MJ is equivalent to millions of joules.

Using the assumptions described above for the consumption rates for the total energy and for the energy from electricity, and the values obtained by the relations (3) and (4), we can obtain the electricity consumption values projected for 2030 (16.04\%) and 2039 (15.88\%). Thus, for 2030, the result of the Brazilian projected electricity consumption demand, $\mathbf{C}_{\mathbf{p c B r e l}}$ would be:

$$
\mathbf{C}_{\mathbf{p c B r e l}}=\left[9.518 \times 10^{-3}(\mathrm{ZJ} / \text { year }) / 216,010,430(\text { inhabitants })\right] \times 0.164=7.07(\mathrm{BJ} / \text { inhabitant year })
$$

and for 2039:

$$
\mathbf{C}_{\mathbf{p c B r e l}}=\left[1.0175 \times 10^{-2}(\mathrm{ZJ} / \text { year }) / 219,124,700(\text { inhabitants })\right] \times 0.158=7.37(\mathrm{BJ} / \text { inhabitant year })
$$

Considering the self-sustained scenario, electricity generation via nuclear power in the years of 2030 and 2039 in Brazil would be approximately $9 \times 10^{-5} \mathrm{ZJ} /$ year, corresponding to $7.1 \mathrm{GW}$ of projected power.

\section{Conclusions}

Taking the current indexes for the world electricity consumption into consideration, pushed up mainly by the developed and highly industrialized countries, and assuming that they are the same for the developing countries, by the time world's population reaches $10^{10}$ inhabitants, calculations show that the power consumption projections for Brazil, for the adopted time horizon and when using global indexes, become overestimated, when compared with the results calculated by our national indexes. According to our studies, power consumption estimates using global indexes becomes approximately 4.5 times higher than the estimates based on national indexes. Global indexes, as taken by several works and particularly the work of Tomabechi [6] analyzed here, are not reflecting the national realities in terms of energy consumption and demand, as is the case of Brazil.

Data here used for the predictions are subjected to changes and to the accuracy of the governmental agencies at the time of their publication. In the Brazilian case, the recent discovered pre-salt oil deposits offer a possibility for a different solution to a possible energy crisis, when compared, for example, to the United States. Together with China and the European Union, they are responsible for almost $65 \%$ of the world's energy consumption, having also combined factors like large population and large energy consumption per capita. Both factors lead to high levels of emissions and to the fast depletion of the current natural resources.

However, despite the great potential of the Brazilian reserves of uranium, water, oil, etc., clean energies must also be taken into consideration in the future, to meet the 2DS requirements. For a non-GHG-emission source, nuclear is the most available candidate. For Brazil, together with the renewables, the nuclear option could be a quick start to solve the problem of emissions due to deforestation, our main source of greenhouse gases.

Construction of nuclear power plants is always a subject for debates and speculation, impacting the forecasts of consumptions of uranium and thorium, by means of a correct campaign for the public acceptance. It was stated above that a way to reach some equilibrium condition could be achieved, however, if countries agree to 
diffuse their energy technologies for other countries, developing or under-developed, since they are at most low carbon emitters and usually still don't have enough technology development to carry out projects on clean energies. Sharing the technologies could be a fast contribution for the solution to the growing problem of climate changes.

Relating to nuclear energy, at least four factors, mentioned is this work, can put Brazil in a comfortable position in front of a possible crisis in the future demand for energy: 1) uranium: since we have enough uranium in the Brazilian territory, and counting with the future improvement of the process of uranium extraction from phosphates; 2) thorium: since Brazil has also enough reserves, for future uses in new technology nuclear power reactors; 3) population growth stability: according to the governmental projections; and 4) nuclear fuel cycle know-how.

Climate instabilities can reach us all in a near future, and global warming is one of its possible triggers. Besides, human activities play a very important role in the contribution to the instability of the weather in a global scale. The increase in the demand for energy, in the population growth, mainly in the last 50 years, leading to the increase of the greenhouse gas emissions and to all the climate instabilities we have been facing, should be assessed considering the appropriate indexes. Thus, according to this work, a different criterion must be stated, for the world to face this problem fairly, since a huge amount of investments will be needed to control or to reduce the threat of the so called "non-turning point" phenomena, in terms of the global weather.

Thus, the future transition between the massive global uses of fossil fuels to a massive global use of the alternative sources, supported by our nuclear know-how, could be carried out in such a way to help us in the improvement of the life quality in our country, and as a consequence, in our planet.

\section{References}

[1] http://www.cia.gov/library/publications/the-world-factbook

[2] Haratyk, G. and Forsberg, C.W. (2012) Nuclear Renewable Energy System for Hydrogen and Electricity Production. Nuclear Technology, 178, 66-82.

[3] Empresa de Pesquisa Energética—EPE (2012) Ministério de Minas e Energia, Balanço Energético Nacional 2012.

[4] http://www.inb.gov.br

[5] IEA (2012) Tracking Clean Energy Progress-Energy Technology Perspectives 2012 Excerpt as IEA input to the Clean Energy Ministerial. 82 p. http://www.iea.org/publications/freepublications/publication/Tracking_Clean_Energy_Progress.pdf

[6] Tomabechi, K. (2010) Energy Resources in the Future. Energies, 3, 686-695.

[7] Statistical Series, Instituto Brasileiro de Geografia e Estatística (IBGE). http://www.ibge.gov.br/series_estatisticas/exibedados.php?idnivel=BR\&idserie=POP300

[8] Piore, A. and Planejando, C.N. (2011) Scientific American Brasil, Edição Especial Energia Nuclear, 7-11.

[9] Cochran, T.B., Feiveson, H.A., Mian, Z., Ramana, M.V., Schneider, M. and von Hippel, F.N. (2010) It’s Time to Give up on Breeder Reactors. Bulletin of Atomic Scientists, 66, 50-56. http://dx.doi.org/10.2968/066003007

[10] World Nuclear Association, WNA (2011) Current Status. http://www.world-nuclear.org/info/reactors.html

[11] (2011) Understanding the Roles of Technology Diffusion, Intellectual Property Rights, and Sound Environmental Policy for Climate Change. World Energy Council WEC Energy Sector Environmental Innovation.

[12] Cerri, C.C., et al. (2009) Brazilian Green-House Gas Emissions, the Importance of Livestock and Agriculture. Scientia Agricola, 66, 831-843. http://dx.doi.org/10.1590/S0103-90162009000600017

[13] Kidd, S. (2011) Uranium Supply for the Nuclear Future. Energy and Environment, 22, 61-66.

[14] Data to Graphics and Tables Extracted from http://www.nationmaster.com.

[15] Geração Termonuclear (2008) Boletim da Empresa de Pesquisa Energética EPE. No. 20080512-7, Ministério de Minas e Energia, Secretaria de Planejamento Estratégico, Maio de 2008, 13.

[16] Gonçalves, O.D. (2011) Brasil Ainda Hesita na Área Nuclear. Scientific American Brasil, Edição Especial Energia Nuclear, 35-39.

[17] Ashley, V., et al. (2010) The Commercially Viable ADTR Power Station. Nuclear Future, 7, 41-45.

[18] www.epe.gov.br/PNE/20070625_09.pdf

[19] Análise Retrospectiva (2008) Boletim da Empresa de Pesquisa Energética EPE. No. 20080512-1, Ministério de Minas e Energia, Secretaria de Planejamento Estratégico, Maio de 2008. 
Scientific Research Publishing (SCIRP) is one of the largest Open Access journal publishers. It is currently publishing more than 200 open access, online, peer-reviewed journals covering a wide range of academic disciplines. SCIRP serves the worldwide academic communities and contributes to the progress and application of science with its publication.

Other selected journals from SCIRP are listed as below. Submit your manuscript to us via either submit@scirp.org or Online Submission Portal.
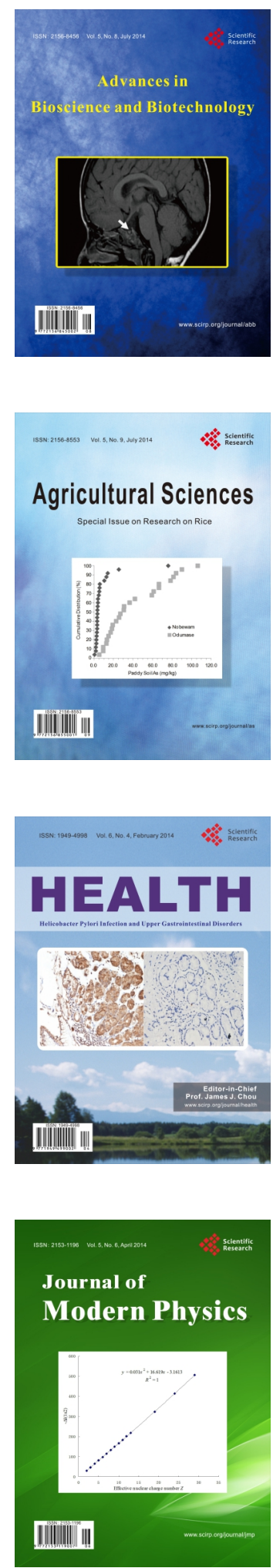
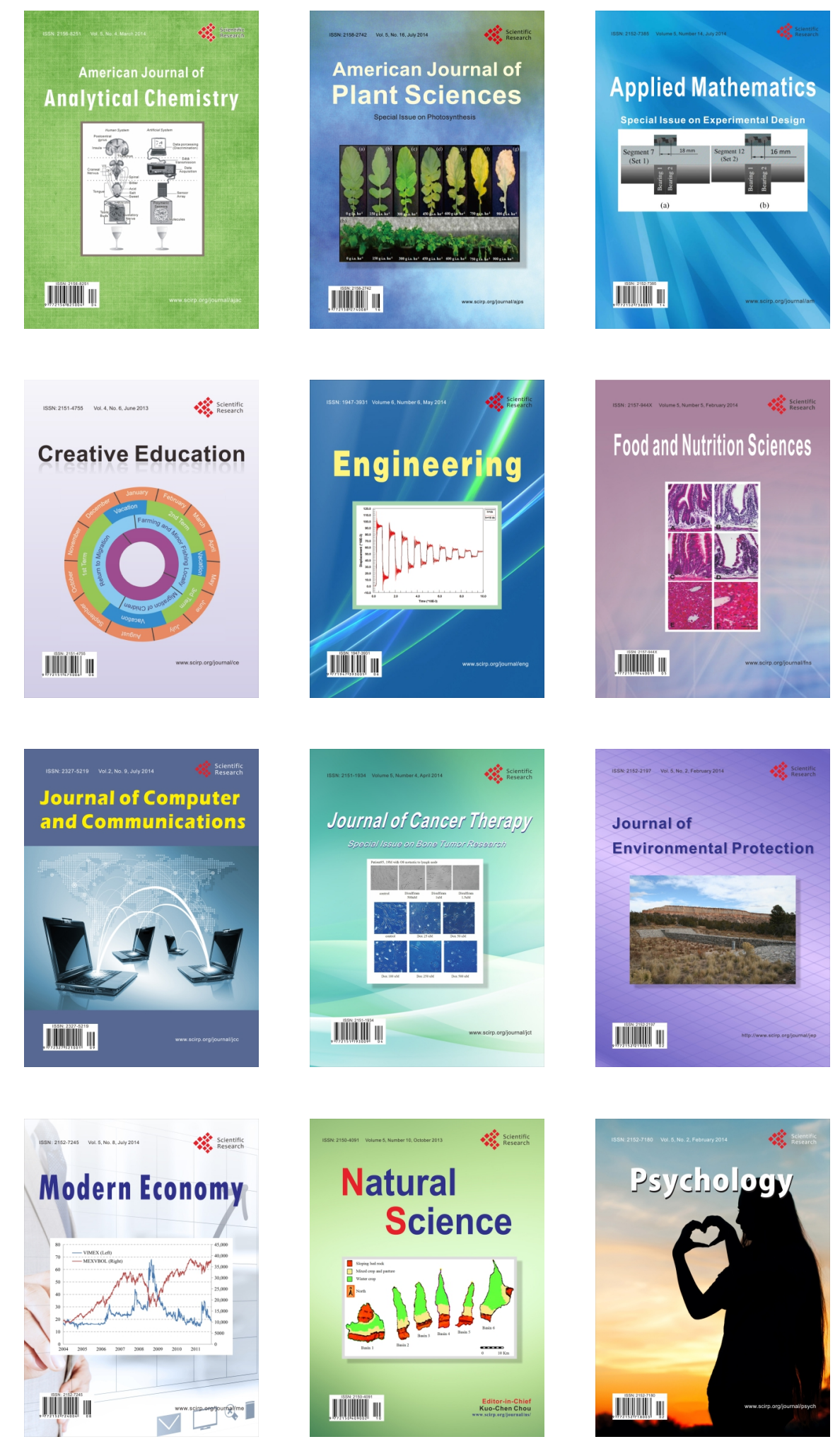